Article

\title{
Data Sensing and Processing Tensioning System Based on the Internet of Things
}

\author{
Xiaowen Chen ${ }^{1,2}$ and Guanci Yang $2, *$ (i) \\ 1 Center for Computer Education and Information Technology, Guizhou Medical University, \\ Guiyang 550025, China; chenxiaowen@gmc.edu.cn \\ 2 Key Laboratory of Advanced Manufacturing Technology of Ministry of Education, Guizhou University, \\ Guiyang 550025, China \\ * Correspondence: guanci_yang@163.com or gcyang@gzu.edu.cn; Tel.: +86-0851-8474-7007
}

Received: 4 December 2018; Accepted: 9 January 2019; Published: 16 January 2019

\begin{abstract}
Tensioning is an important process for producing prestressed concrete beams and directly affects bridge performance and driving safety. Active sensing and management of tensioning process data can improve the efficiency of quality monitoring and level of prestressed concrete beams. To realize remote collection and quality monitoring of tensioning process data, a framework for data sensing and processing of tensioning system based on the Internet of Things (IoT) is proposed in this study. Firstly, we investigate the technical framework and techniques of the system and designs a work flow of sensing, transport, and application service layers. The architecture of the tensioning system is presented. Then we propose a data acquisition and preprocessing method for the sensing layer, put forwards the data-pushing mechanism of the transport layer, and designs the function and work flow of the application service layer. After that, .NET platform and Android Studio are used to implement the tensioning system based on Browser/Server (B/S) architecture and mobile terminals. Finally, the case results of the system in seven precast beam fields in the Hubei section of Zhengzhou-Wanzhou high-speed Railway are given, which show that the developed system realizes collection, active pushing, and remote monitoring of tensioning process data.
\end{abstract}

Keywords: Internet of Things; prestress tensioning; quality monitoring; intelligent perception; prestressed concrete beam

\section{Introduction}

Prestressed concrete beams are widely used in highway and railway construction [1], and their production process consists of four steps, namely, template installation, reinforcement assembling, concrete pouring, and prestress tensioning. Prestress tensioning is an important measure to improve the tensile strength of concrete [2-6], and its results directly affect the performance and quality of bridges $[7,8]$. The development of numerical control technology and smart devices has made intelligent tensioning a mainstream technology. Liao et al. [9] introduce the main working principle, technical process, and operating points of intelligent tensioning and provide practical experience for the application of an intelligent tensioning construction technology in road prestressed construction. Dong et al. [10] describe the application of an intelligent tensioning system in a box girder with a length of $30 \mathrm{~m}$, which effectively reduces the problems in manual tensioning and improves the prestressed construction quality. Liang [11] develops an intelligent synchronous tensioning system that allows precise control of tensioning force and strand elongation. Xiao et al. [12] realize the automatic acquisition of tensioning force and displacement data, calculate regression coefficients, and present regression equation, which forms a relation curve of force and displacement. Intelligent tensioning can improve the precision of tensioning operations but lacks the management of monitoring, which 
can lead to the risk of false data. To grasp the situation of tension quality in real time, Yang et al. [13] study the full automation and remote monitoring methods of prestress tensioning process based on intelligent tensioning and large circulation grouting principle. Xiong [14] proposes the research idea of intelligent tensioning complete equipment based on the Internet of Things (IoT) and introduces expert systems and remote monitoring to improve the management level of tensioning. The remote monitoring system in the above-mentioned studies barely considers human-computer interactions and lacks pushing functions for active reminders and notifications; therefore, manual data input is still in need.

The development of technologies, such as IoT, radio frequency identification (RFID), and wireless sensing, has enabled the dynamic perception and automatic collection of construction process data [15-17], thereby providing managers with construction quality control and a basis for scientific decisions of follow-on production schedules [18]. Zhan et al. [19] propose a real-time enterprise architecture based on smart items and define the basic concepts of events, event models, and hierarchical models. Lu et al. [20] propose a collaborative manufacturing framework based on IoT, which provides a basis for the network physical interaction and collaboration in advanced manufacturing. Zhang et al. [21] propose a Framework of the Internet of Manufacturing Things (IoMT) and analyze and design key technologies, such as sensor network configuration, sensing and capturing of manufacturing data, data processing, and application services. Zhao et al. [22] propose the concept of IoT-based manufacturing system and design key technologies, such as dynamic optimization of manufacturing process, online production quality control, and diagnostics and tracking. Tao et al. [23] propose an IoT-based five-layer structure (i.e., resource, perception, network, service, and application layers) and design the key technologies of intelligent perception and access of various resources in cloud manufacturing. Chen et al. [24] build an active perception and management technology framework for manufacturing data based on the event perception model to address the perception and management of IoMT data. Huang et al. [25] propose an economical improving method for job shop performance that automatically obtains real-time data of job shops using sensors and wireless devices. Li et al. [26] design and implement a novel complex event-processing engine to detect the occurrence of real events by real-time matching atomic events with complex event patterns, which improves the processing speed of IoT. Li et al. [27] study the key technologies of active sensing and processing of complex production events, build an active sensing model, and establish the technology architecture and techniques for active sensing and processing of complex events based on IoT. IoT-based remote monitoring has been applied in multiple industries. Akl et al. [28] monitor constructed wetlands in real time with web applications, and the results prove the feasibility and innovation of the Internet monitoring of constructed wetlands. Islam et al. [29] use a motion sensor and an ultrasonic sensor to measure target distance precisely, which reduces the memory consumption of monitoring system. Lian et al. [30] develop a remote monitoring system for poultry farming environment based on IoT, which uses sensors to monitor the temperature, humidity, and other important indicators of the farming environment and remotely manages data and monitors the environment in real time with a computer or mobile terminal.

The contributions of our work mainly include:

- Investigated the technical framework and techniques of a system and designs a work flow of sensing, transport, and application service layers to realize collection and quality monitoring of tensioning process data, and proposed the architecture of the intelligent tensioning system.

- Proposed a data acquisition and preprocessing method for the sensing layer, put forward the data-pushing mechanism of the transport layer, and designed the function and work flow of the application service layer.

- Implemented the intelligent tensioning system based on browser/server (B/S) architecture and APP mobile terminals by using .NET platform and Android Studio.

The rest of this paper is organized as follows. Section 2 reviews the related technical. Section 3 introduces intelligent tensioning system design. Section 4 presents system implementation. Section 5 
describes application cases and analysis. Section 6 concludes the paper and discusses future research issues.

\section{Technical Framework and Analysis}

The IoT-based intelligent tensioning system combines prestressed tensioning devices, IoT, and electronic information and communication technologies to control oil pumps, superchargers, valves, oil tops, and other equipment with digital instructions. The system uses various intelligent sensors to implement automatic job data collection and structured encapsulation and pushes field job data to the cloud server in real time using a computer telecommunication technology. The data are then pushed from the cloud server to the mobile terminals of constructors, supervisors, and proprietors to implement the management functions of automatic data sensing and collection, process data pushing, and remote monitoring. The system architecture is shown in Figure 1.

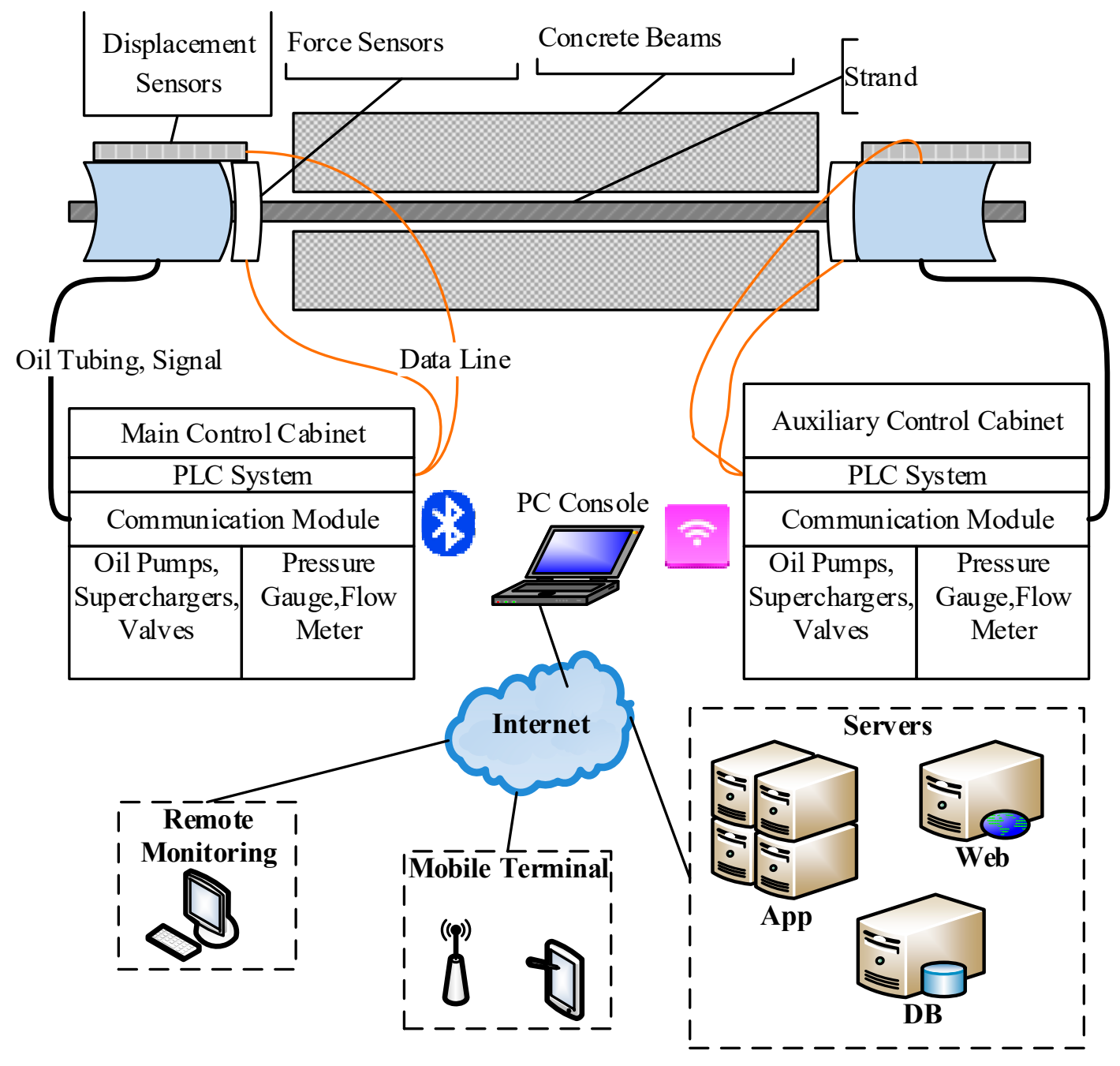

Figure 1. Tensioning system architecture.

In accordance with the development trend and application model of IoT and combining the layered IoMT architecture with the requirements of prestressed tensioning system, the IoT-based intelligent tensioning system is divided into three layers of sensing, transport, and application service layers, as shown in Figure 2. The entire architecture mainly includes six layers of data acquisition, internal transport, data preprocessing, pushing and receiving, data processing, and application. 


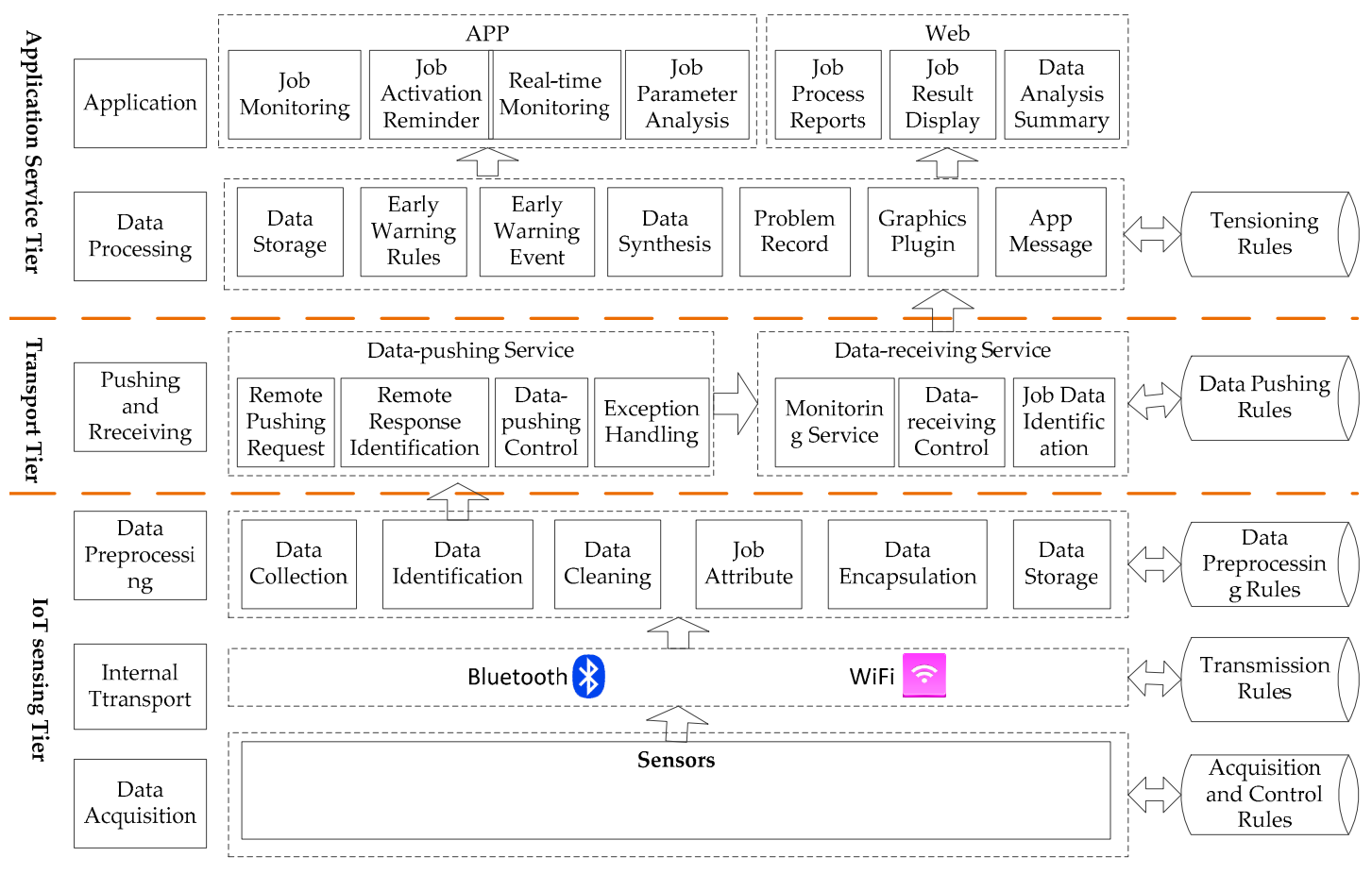

Figure 2. Tensioning system structure.

\subsection{IoT Sensing Layer}

IoT sensing layer is the data-driven source for the entire model. Its main tasks include (1) data acquisition, which uses force and displacement sensors to collect data and combines the data with the sensor's unique ID attribute to form a perceptual data element; (2) internal transport, which transports the perceptual data elements to data-preprocessing center via Bluetooth or WiFi; (3) data preprocessing, which identifies and cleans data elements and deletes redundant or invalid data elements in line with the rules. This layer also implements structured encapsulation with tensioning job parameters and attributes to form structured packets and their local storages. A model of the sensing layer shown in Figure 3 is established on the basis of the perceptive mode of intelligent tensioning.

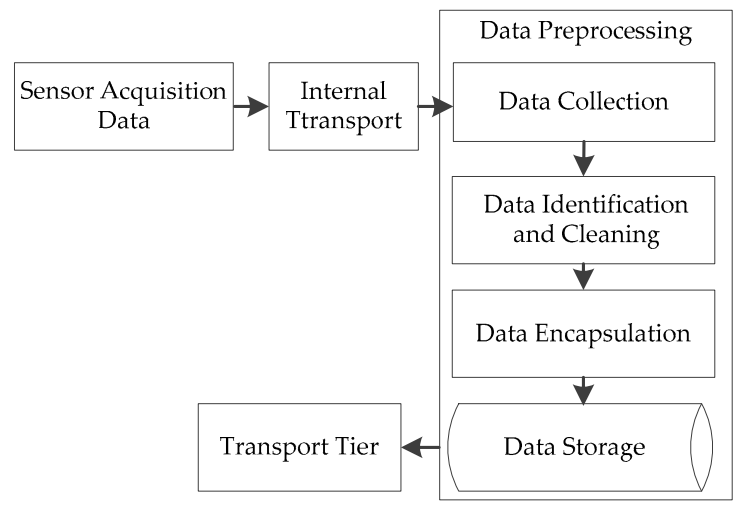

Figure 3. Model of IoT sensing layer.

\subsection{Transport Layer}

The transport layer mainly pushes the structured packets encapsulated by the sensing layer from the operation site to the cloud server, and it consists of two services, namely, data pushing, and data receiving. The data-pushing service is located on the PC console of the operation site, and the data-receiving service is located on the remote cloud server. The data-pushing service consists 
of four sub-services, namely, remote pushing request, remote response identification, data-pushing control, and exception handling. The data-receiving service consists of three parts, namely, monitoring service, data-receiving control, and job data identification. Packet transport mechanisms and rules are established to ensure its integrity and security during transport. The transport layer follows three rules. First, the encapsulated structured packets are taken as transport units. Second, pushing request, answer response, data-pushing and data-receiving control, exception handling, and other services are required between data-pushing and data-receiving services. Third, the receiving service performs unpacking inspection on packets in accordance with the data encapsulation and pushing rules and discards noncompliant packets to avoid junk data or malicious attacks.

\subsection{Application Service Layer}

The application service layer consists of a data-processing layer and an application layer. The data-processing layer processes data in line with the rule base of tensioning operations, and the application service layer provides app and web application services. The main tasks of the application service layer include (1) storing packets that match the rule; (2) detecting data items in the packets in accordance with the warning rule and triggering warnings depending on conditions; (3) extracting data items in job packets and synthesizing job data in line with job rules; (4) completing the pushing service of app messages; (5) completing the service monitoring and data browsing of app terminals; and (6) implementing the display function of web pages data.

\section{Intelligent Tensioning System Design}

On the basis of the above-mentioned technical architecture and analysis and combined with the management requirements of the tensioning process, the data collection, cleaning, and encapsulation of each sensor are performed in accordance with rule base. The packets are pushed from the operation site to the remote cloud server by the data-pushing and data-receiving services of the transport layer. The data-processing layer processes packets in line with rule base, and the final application layer presents data to users via app and web pages.

\subsection{Operation Flow}

Taking multiple prefabricated beam fields as application scenarios, each beam field has multiple tensioning devices, and the working time of each tensioning device is random. On-site data transport mainly depends on mobile terminal networks. thus, the transport speed, and transport cost of the network application layer should be considered. The operation flow comprises four steps. First, the control engine is started, and each sensing node is activated and is in ready mode, which will respond to the data acquisition instruction by the control engine at any time and then send the current measured value back to the control engine. Second, the monitoring sub-service of the transport layer continuously monitors the transport requests from the operation site. When a tensioning job is started at the operation site, the on-site PC controller will send a data push request to the remote server. The server decomposes and verifies the request data immediately when monitoring the received request data. If the data are confirmed a legitimate request, then the server will give confirmation feedback and prepare for data reception. If no data are detected from the pushing end for a long time, then the transport channel will be automatically closed, thereby maximally saving the resources and costs of network communications. Third, the tensioning process packet has a high sampling frequency, large data volume, and other features. The data-receiving service needs to receive data from different tensioning devices at the same time. At the receiving side, the temporary data table is used as a buffer area. When receiving data, the data is immediately written to the temporary table and the corresponding service of the data processing layer is started, thus improving the speed of data writing and service response. After the end of the tensioning operation, the data in the temporary data table is transferred to the historical data table. Fourth, the job monitoring service of the mobile terminal App 
is monitoring the tensioning operation. When the tensioning data is monitored, the tensioning process data is displayed in a curved manner, thereby realizing remote monitoring.

\subsection{Data Encapsulation}

Tensioning job data comprise tensioning parameters, No. 1 channel data, and No. 2 channel data, as shown in Figure 4. On the basis of the characteristics of the data sensed during operations and the tensioning process, the data types are divided into flag, conclusion, and process. Flag packets (F) store the parameters and basic information of the tensioning job; conclusion packets (C) store the detection values of tensioning jobs at various stages and are reflections of various technical indicators of tensioning jobs; and process packets $(\mathrm{P})$ continuously record the changing trend of each indicator in the entire operation process. The performance of the reading, analysis, and storage of data transport is considered comprehensively. Data security is combined with network transport cost, and the job data are encapsulated into a structured packet. The packet structure is shown in Figure 5. The packet is composed of data blocks, such as packet header, job number, data length, data type, job data, and check bit. According to the above rules, the structure of process packets is shown in Table 1.

Table 1. Structure of process packets.

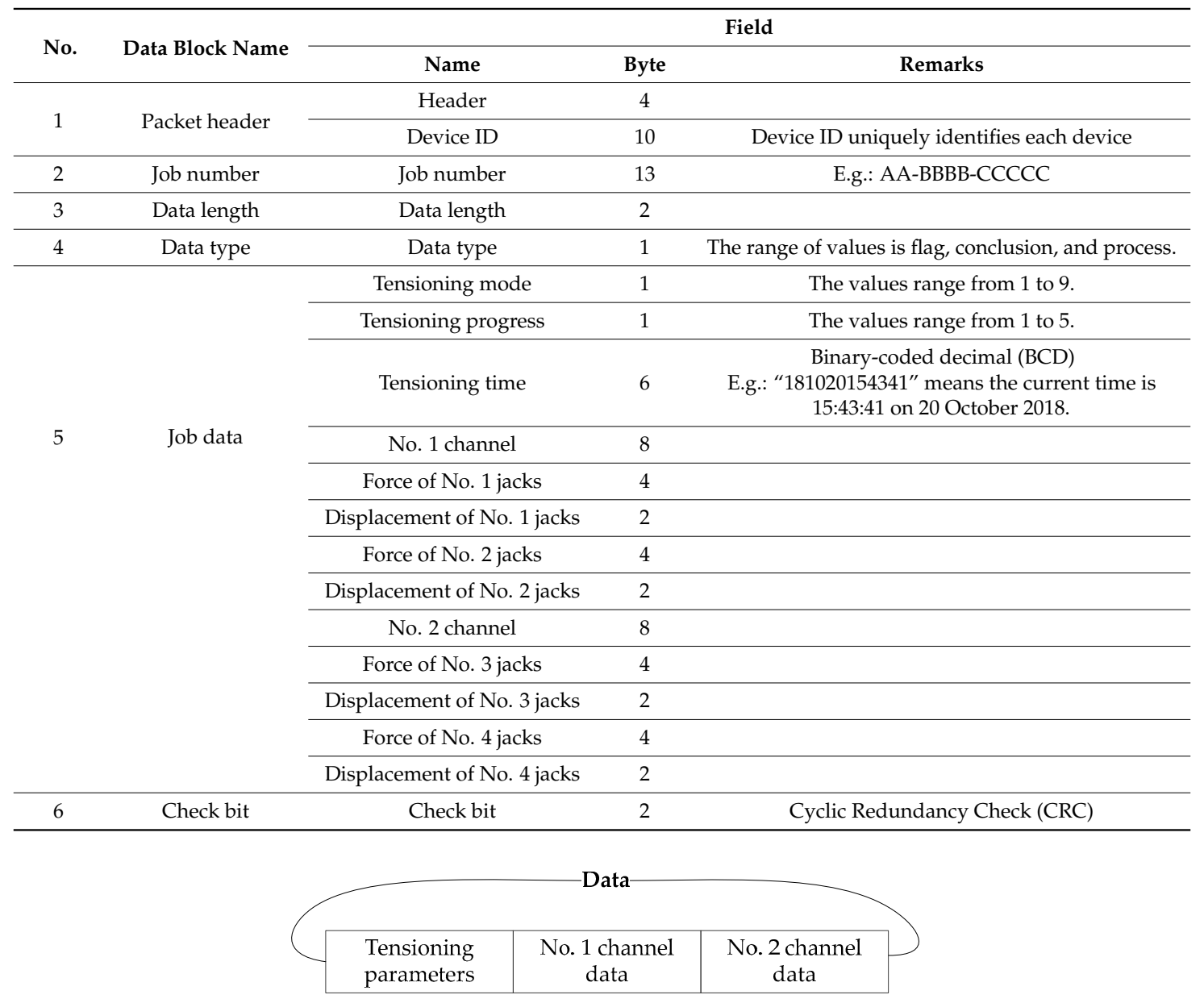

Figure 4. Job data structure.

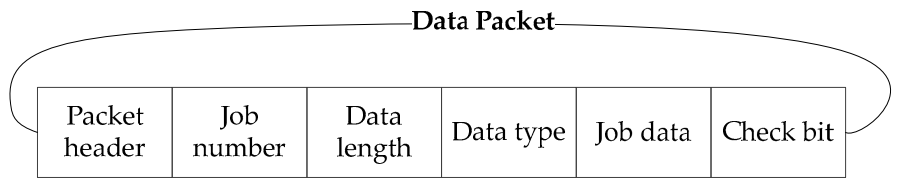

Figure 5. Structure of structured packets. 


\subsection{Pushing and Receiving}

The transport of structured packets depends on data-pushing and data-receiving services. SOCKET communication technology has the characteristics of small amount of data transmission, fast transmission and security. Therefore, it is used to push data from the job site to the remote cloud server. In practical application, many tensioning devices will be distributed in different beam fields. Each tensioning operation is random, and each operation is about $12 \mathrm{~min}$. Only in tensioning operation, the sender will actively establish a connection channel with the receiver and carry out data transmission. The monitoring service in the data-receiving service is in the monitoring state at any time. When the request from the data-pushing end is monitored, it is identified in accordance with the rules in the transport rule base, and the rule-matching information is returned. When a condition in the transport rule base is satisfied, a transport channel is developed between the server and users. After receiving packets, the data-receiving service selects and rejects them in line with the rules. The exception-handling service at the pushing end deals with transport errors or network anomalies.

\subsubsection{Transport Mechanism}

Tensioning jobs will generate multiple packets, including two flag packets, four conclusion packets, and $n$ process packets. The flag packets appear at the head and tail of the entire packet sequence. Flag packet 1 marks the beginning of the job, and flag packet 2 indicates the end of the job. The process packets contain data of several time points, which are arranged in sequence between the flag packets according to collection time. The packet arrangement order is shown in Figure 6.

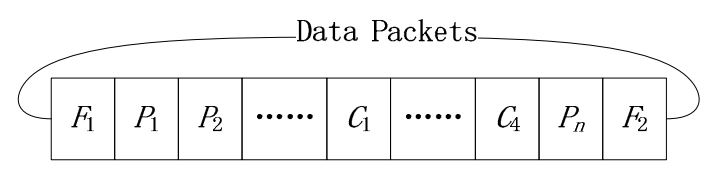

Figure 6. Packet arrangement order.

In the process of packet pushing and receiving, network anomaly is an important affecting factor of data integrity. In this study, a packet queue response mechanism is adopted to ensure data integrity. First, the packet queue is initialized when the job is started, and the packet is enqueued during the operation. Second, the data-pushing service reads the header packet and pushes it. Third, after receiving the confirmation message returned by the remote server, the data-pushing service performs dequeuing operations. The flow of the packet queue control mechanism is shown in Figure 7.

During the data push process, the exception handing service is activated when an acknowledgment message from the remote server is not received. The service writes error information to the $\log$ file and select the operation according to the cause of the error. When it is not a network problem, the data is pushed again. When the cause of the error is a network problem and the tensioning operation has ended, the data in the packet queue is recorded, and the data-pushing service is ended. Otherwise, continue the current data-pushing service.

\subsubsection{Transport Flow}

The sequence diagram of the packet transport based on the above-mentioned transport mechanism is shown in Figure 8. The specific transport flow is divided into seven steps. First, startup commands are sent out from the PC console before tensioning jobs to start or wake up the sensing layer and data-pushing service. A "connecting request" is sent to the remote server by using a remote pushing request. Second, after receiving the connecting request, the monitoring service identifies the request information in accordance with the request rules in rule base and returns the result. Third, when the response result is "err", the exception-handling service is called to record the exception information and return the connection failure result to the PC console; if it is "ok," then the pushing control service is called to send the "request for establishing channels". Fourth, after receiving the request, the 
receiving control establishes a data transport channel and is ready to receive data. Fifth, the header of the packet queue is read by the pushing control and pushed to the receiving control service. Sixth, after receiving the data, the receiving control service identifies the legality and type of the data and returns the result to the pushing control service. Seventh, the result is received and identified by the pushing control service. When it is "yes," the packet queue is dequeued, and a "true" is returned to the PC console; when it is "no," the exception-handling service is called, and a "false" is returned to the PC console.
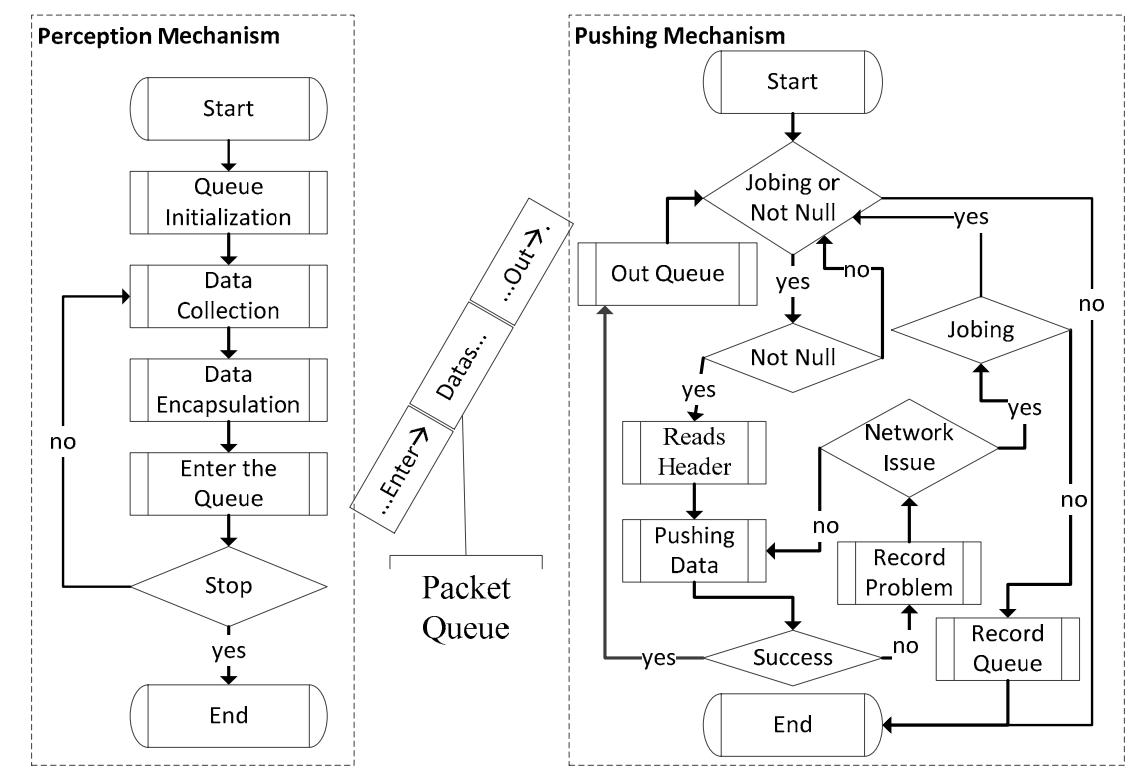

Figure 7. Packet queue control mechanism.

In the transport layer, the following measures are taken to ensure the integrity of the tensioned data. First, at the sending side, the packet queue control mechanism is used to ensure orderly pushing of data, and the exception handing service is started when an abnormality occurs. Second, CRC method is used to check the integrity of data packets at the data receiving side to prevent data block loss in data packets.

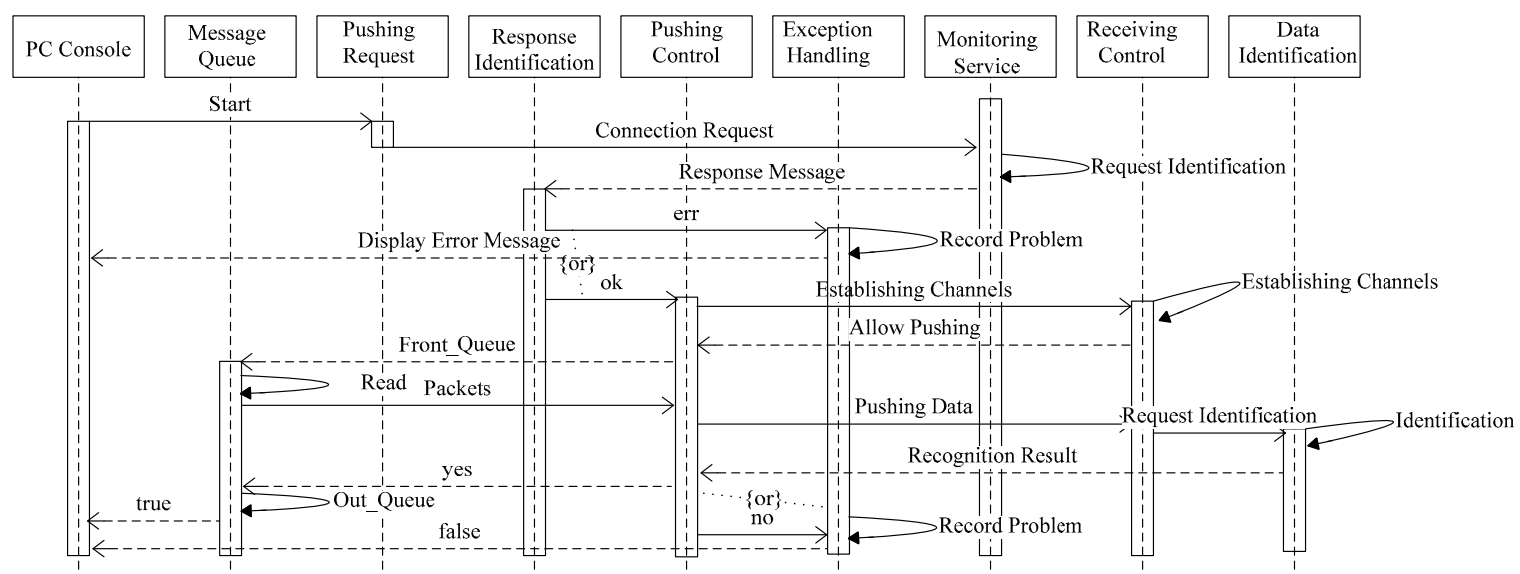

Figure 8. Packet transport sequence diagram.

\subsection{Data Processing}

After receiving a valid job packet, the data-processing layer identifies and extracts it successively. The data-processing layer includes five operations. First, the packet is split, each data item is extracted, 
and the data are stored to the corresponding data table according to packet type. Second, the pre-alarm parameters and reference values in the rule base are extracted and compared with the corresponding data items. Third, when the value of the data item exceeds the warning reference value, a job problem is automatically generated and written to the problem base. Fourth, job data are synthesized, the synthetic construction record table for each data item is extracted in accordance with the management specification and business rules of tensioning jobs, and the job data are summarized automatically. Fifth, when the tensioning job is started or an alarm event is triggered, the app message service is started to push corresponding prompt messages and job data to administrators. The specific operation flow of the data-processing layer is shown in Figure 9.

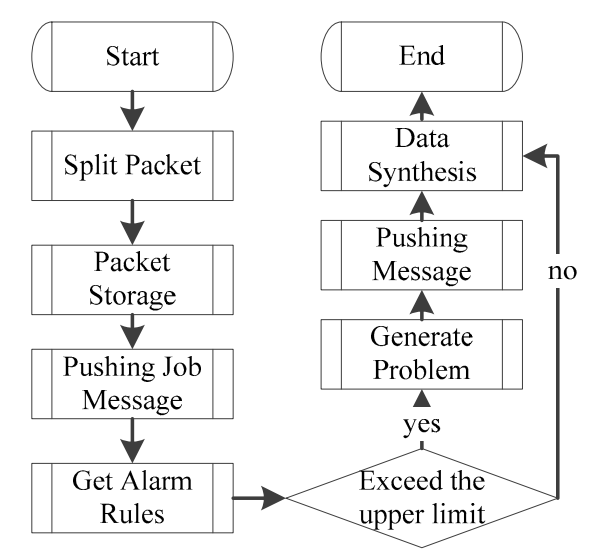

Figure 9. Data-processing layer operation flow.

Data synthesis is a key step in the data-processing layer. A series of operations, such as extracting, analyzing, and synthesizing, is performed on flag and conclusion packets in line with the business rules to provide data support for the application layer. The data synthesis process is shown in Figure 10.

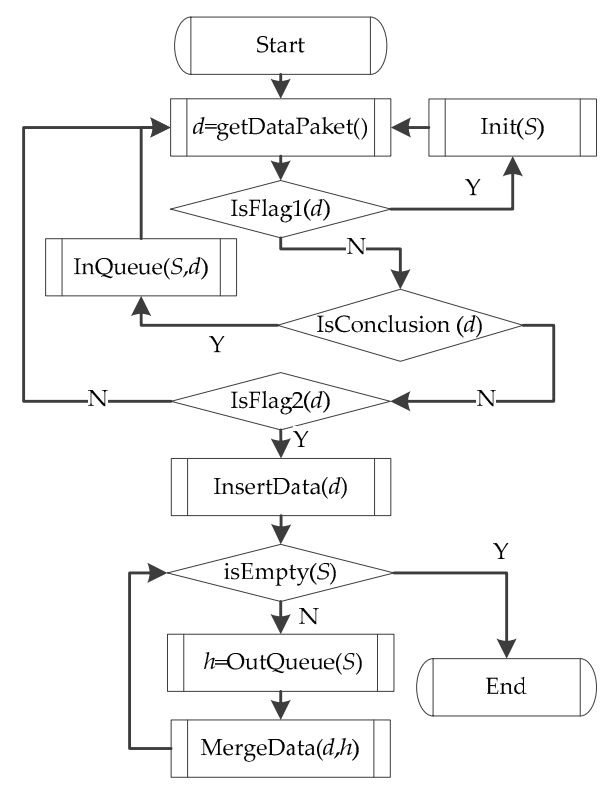

Figure 10. Data merging process.

The tensioning jobs are divided into types $\mathrm{A}, \mathrm{B}$, and $\mathrm{C}$ according to the quantity of jacks in need during tensioning jobs. Type A indicates that the No. 1 and 2 channels are simultaneously operated, Type B indicates that only No. 1 channel is in operation, and Type C indicates that only No. 2 channel is in operation. The specific algorithm for data merging is shown in Algorithm 1. 


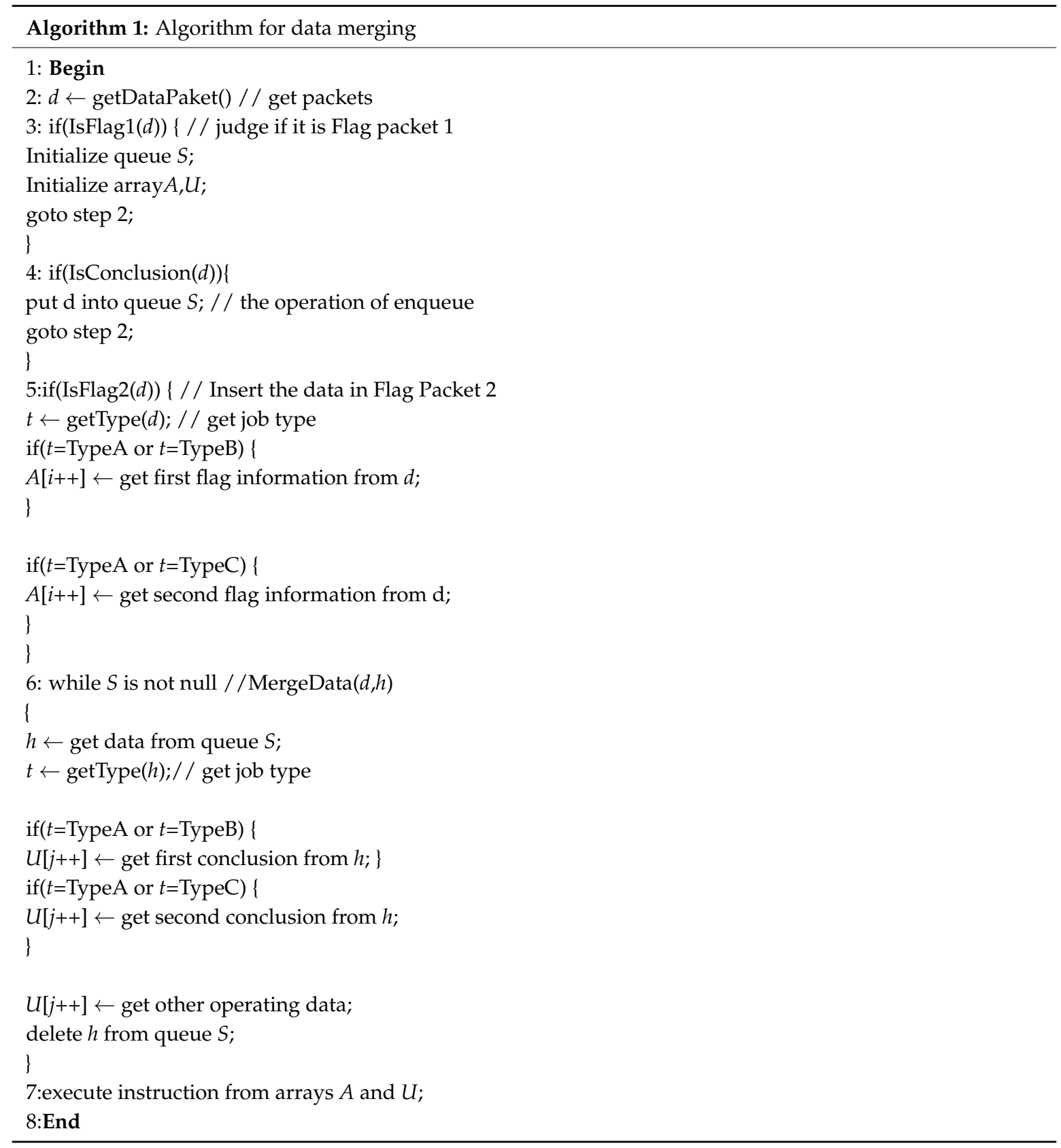

\subsection{Application Layer}

The application layer consists of APP and web pages, with mobile terminal APP and PC browsers as display media.

(1) The APP for mobile terminal consists of job monitoring, job activation reminder, remote monitoring, and job parameter analysis. The job-monitoring service, which gives text and voice reminders after detecting push messages, comes from Google's personal push messages. When the tensioning job is started on-site, the server immediately pushes the job start reminder to the mobile terminal. The remote job monitoring requests job data from the server in polling mode, displays force and displacement data with curves, gives warnings on measured values that exceed the warning, and performs statistical analysis on the job parameters. The transport between the app terminal and the server adopts a lightweight JSON data format, which reduces the difficulty of computer generation and analysis and improves network transport efficiency. 
(2) The web pages consist of job process reports, job result display, and data analysis summary. A two-dimensional table is used to display the changes in each force and displacement during the entire operation process. The changing trend is described by curves and compared with the theoretical design value and the trend of the curve. Each job control indicator is displayed in terms of channels, and a tensioning construction record table is formed. The monthly workload, normal number, and normal rate are shown in charts, and the actual data are compared with theoretical calculation values.

\section{System Implementation}

An intelligent tensioning system based on IoT is developed in accordance with the previous technical architecture and design. The system is composed of a web program based on B/S architecture, a mobile terminal-based app, and the data transport service, which realizes functions, such as automatic data sensing, remote pushing, remote monitoring, and application services.

(1) An Android-based APP with Android Studio 3.0 is developed as the development language. The specific functions are shown in Table 2.

Table 2. APP function list.

\begin{tabular}{|c|c|c|}
\hline No. & Function Name & Description \\
\hline 1 & Job reminder & $\begin{array}{l}\text { When a tensioning job is detected on-site, a job message is pushed to the app } \\
\text { in time, and the job monitoring is automatically started via the job message. }\end{array}$ \\
\hline 2 & Job monitoring & The job data pushed on-site are monitored in time, and a job list is monitored. \\
\hline 3 & Remote monitoring & $\begin{array}{l}\text { Certain job data are monitored in time, and the process data and changing } \\
\text { trends of force and displacement are shown with continuous curves. }\end{array}$ \\
\hline 4 & Job analysis & Changes in force and displacement during tensioning operations are analyzed. \\
\hline
\end{tabular}

(2) The system is developed using the .NET 4.5 Framework and the SQL Server2008 database along with Visual Studio 2012 integrated environment C\# as the development language and web as the development template. The specific functions are shown in Table 3.

Table 3. Web pages function list.

\begin{tabular}{lll}
\hline No. & Function Name & Description \\
\hline 1 & Job reports & $\begin{array}{l}\text { A construction record chart of tensioning job data is automatically generated } \\
\text { to record the job data of each beam channel. }\end{array}$ \\
& (1) The results of various tensioning operations are displayed, and detailed \\
operation information of each channel is shown. \\
(2) Tensioning and displacement at both ends are analyzed. \\
(3) Trend analysis of tensioning force and displacement at the same end is \\
conducted. \\
(4) Contrastive analysis between the designed initial stress and the actual \\
tensioning force is performed, and the duration when they match with each \\
other is determined. \\
(5) Contrastive analysis between the designed control stress and the actual \\
tensioning force is conducted, and the duration when they match with each \\
other is identified.
\end{tabular}

(3) The data-pushing and data-receiving modules are developed using SOCKET programming along with Visual Studio 2012 integrated environment C\# as the development language and Windows as the development template. SQL Server database is shared by the data receiver and the web. 
(4) Data acquisition, identification, and encapsulation, as well as the data collection, internal transport, and data preprocessing of the tensioning devices, are performed by manufacturers on the basis of the data encapsulation standards in Section 3.2.

(5) Data follow three principles in the aspects of perception, transport, and application display. First, after data are collected during operation, the tensioning device uses the data-pushing service developed in this study to push the encapsulated packet to the remote server. Second, the data-processing layer uses Google's personal pushing SDK service to push job alerts and warning messages to the app. Third, the app interacts with the application server through the WebService interface.

\section{Case Study and Analysis}

The IoT-based intelligent tensioning system implemented in this study is applied to seven precast beam fields in Zhengzhou-Wanzhou high-speed Railway (Hubei section). Tensioning devices are provided by multiple manufacturers. Manufacturers only need to follow the data encapsulation standards proposed in this study, and the system can be integrated via data-pushing services. The scene of tensioning operation is shown in Figure 11. In the tensioning operation, the sensors we selected are shown in Figure 12.

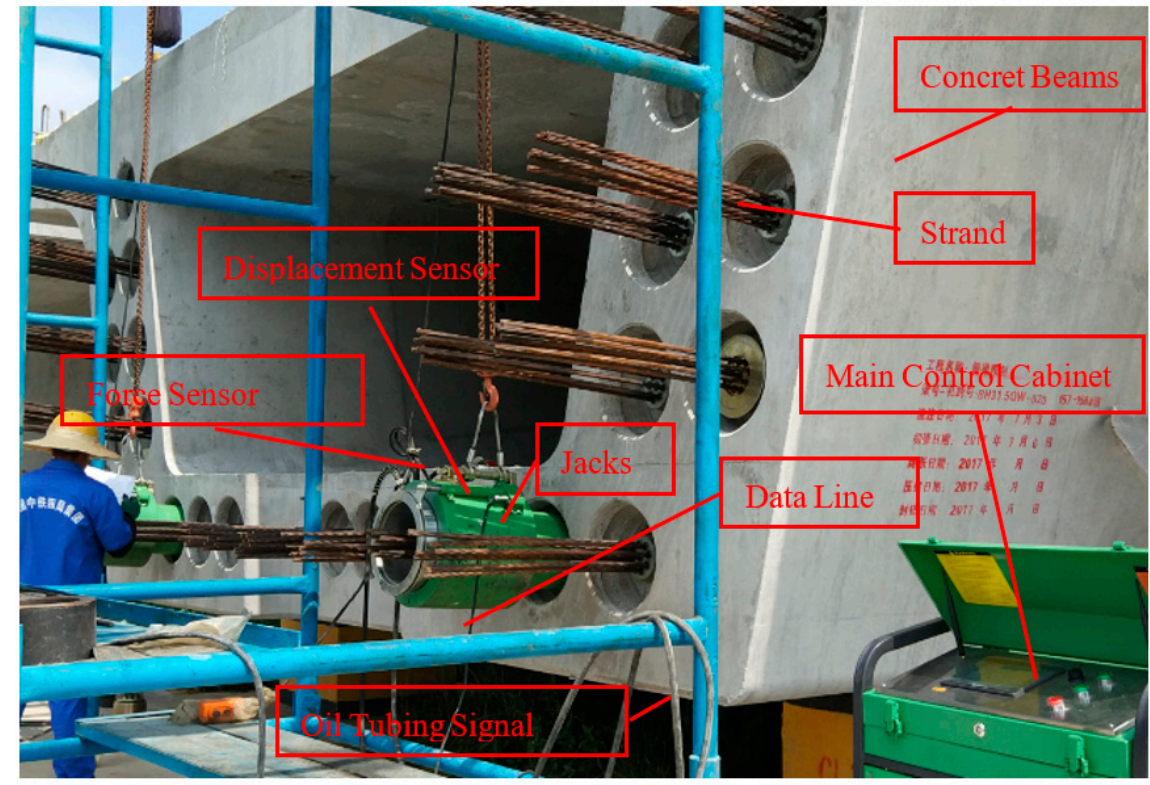

Figure 11. Scene of tensioning operation.

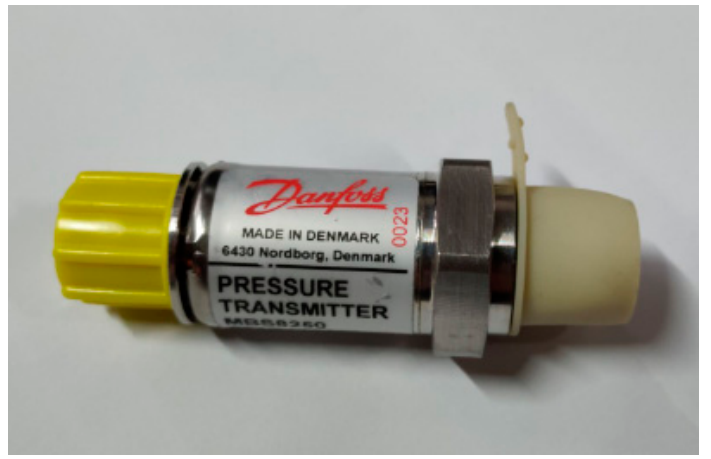

(a)

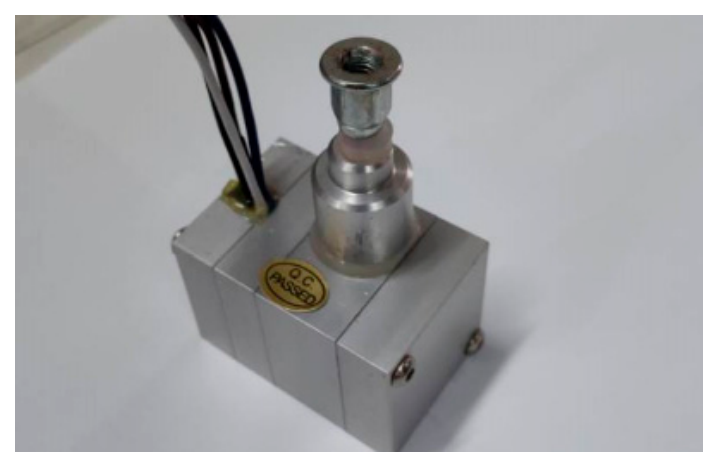

(b)

Figure 12. Sensor selected for tensioning operation. (a) Force sensor. (b) Displacement sensor. 


\subsection{Equipment Parameters}

The tensioning devices provided by manufacturers shall meet the requirements of the tensioning process for railway concrete beams, which are indicated in Table 4 .

Table 4. Parameter requirements of tensioning equipment.

\begin{tabular}{cclc}
\hline No. & Equipment & Parameter Requirements & Quantity \\
\hline 1 & Jacks & & 4 \\
\hline 2 & Force sensor & The error is less than 0.5\%FS. & 4 \\
\hline 3 & Displacement sensor & The error is less than 0.25\%FS. & 4 \\
\hline 4 & Communication module & $\begin{array}{l}\text { The data transport from sensors to PC } \\
\text { console is supported, and wireless } \\
\text { transmission distance is not less than 200 m }\end{array}$ & 1 \\
\hline 5 & PC control machine & $\begin{array}{l}\text { Ordinary PC or notebook, with Win7 system, } \\
\text { is utilized. Data-pushing service is installed. }\end{array}$ & 1 \\
\hline 6 & Mobile communication terminal & Support 4G network. & 1 \\
\hline
\end{tabular}

\subsection{Application Display and Analysis}

\subsubsection{Remote Monitoring}

When the tensioning device is started on-site, the job data are pushed to the server through the transport layer, and the job prompt information is pushed to the apps on mobile terminals by the application service layer via Google's personal pushing service. The app then obtains the various information of the current job from the server according to the prompt message and displays it with curves, as shown in Figure 13, which depicts the changing curves of the force and displacement. The curves in Figure 13 are the data of channel ZN8 monitored in the time range from 8:8:50 to 8:9:14. The internal relations between the force and displacement can also be analyzed.

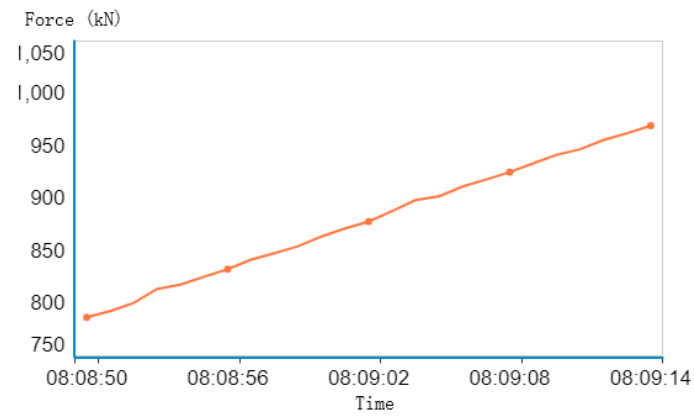

(a)

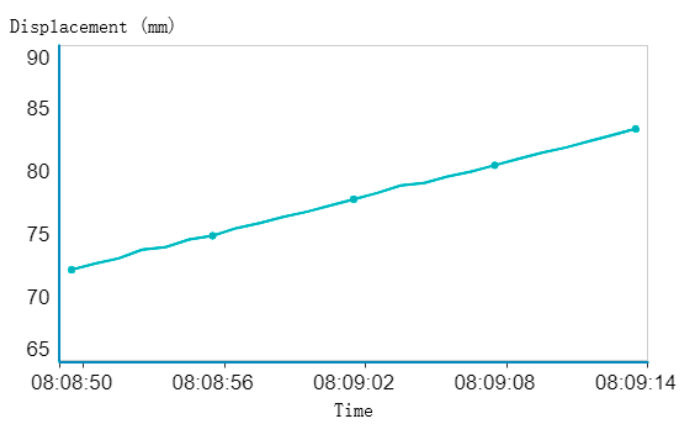

(b)

Figure 13. Tensioning equipment and data monitoring. (a) The changing curves of force. (b) The changing curves of displacement.

\subsubsection{Abnormal Warning and Conclusion Analysis}

The data-processing layer analyzes the received data according to the warning rules. When the warning condition is met, the system pushes the alarm information to the manager's mobile APP, so that the manager can grasp the abnormal data as soon as possible. The data-processing layer will also convert the received data packets into tensioning records according to the tensioning rules. The tensioning record table presents the inspection results of each channel in all control stages of the tensioning process, which cover initial stress, control stress, elongation value, deviation, and other important control indicators, as shown in Table 5. During the tensioning operation, when the value of the deviation exceeds plus or minus 6\%, the manager's mobile APP will receive an abnormal message. 
Table 5. Tensioning records.

\begin{tabular}{|c|c|c|c|c|c|c|c|c|c|c|}
\hline \multirow{3}{*}{ No. } & \multirow{3}{*}{ Channel } & \multicolumn{2}{|c|}{ Force $(\mathbf{k N})$} & \multicolumn{6}{|c|}{ Displacement (mm) } & \multirow{3}{*}{$\begin{array}{c}\text { Deviation } \\
(\%)\end{array}$} \\
\hline & & \multirow[b]{2}{*}{ Initial } & \multirow[b]{2}{*}{ Control } & \multicolumn{2}{|c|}{ Initial } & \multicolumn{2}{|c|}{ Control } & \multirow[b]{2}{*}{ Calcula-Tive } & \multirow[b]{2}{*}{ Theore-Tical } & \\
\hline & & & & $\begin{array}{l}\text { No. } 1 \\
\text { Jacks }\end{array}$ & $\begin{array}{l}\text { No. } 2 \\
\text { Jacks }\end{array}$ & $\begin{array}{l}\text { No. } 1 \\
\text { Jacks }\end{array}$ & $\begin{array}{l}\text { No. } 2 \\
\text { Jacks }\end{array}$ & & & \\
\hline 1 & ZN8 & 338.8 & 1694.1 & 48.2 & 47.1 & 135.6 & 137.1 & 208.4 & 198.4 & 5.0 \\
\hline 2 & YN8 & 338.8 & 1694.1 & 49.5 & 47.4 & 137.5 & 128.7 & 198.2 & 198.4 & -0.1 \\
\hline 3 & ZN9 & 345.6 & 1728.2 & 49.0 & 47.8 & 135.3 & 134.9 & 203.4 & 198.6 & 2.4 \\
\hline 4 & YN9 & 345.6 & 1728.2 & 46.9 & 45.4 & 134.1 & 126.6 & 197.1 & 198.6 & -0.8 \\
\hline 5 & ZN1a & 450.0 & 2249.9 & 44.2 & 44.6 & 129.3 & 132.7 & 203.1 & 198.4 & 2.8 \\
\hline 6 & $\mathrm{ZN} 2 \mathrm{~d}$ & 1289.0 & 1687.4 & 35.3 & 37.4 & 63.9 & 65.8 & 199.4 & 201.4 & -1.0 \\
\hline 7 & YN2d & 1289.0 & 1687.4 & 29.5 & 29.0 & 57.4 & 60.7 & 200.1 & 201.4 & -0.7 \\
\hline 8 & $\mathrm{ZN} 2 \mathrm{a}$ & 1289.0 & 1687.4 & 36.3 & 36.7 & 63.9 & 64.2 & 195.9 & 201.4 & -2.7 \\
\hline 9 & YN2a & 1289.0 & 1687.4 & 33.0 & 32.5 & 62.3 & 56.8 & 195.5 & 201.4 & -2.9 \\
\hline 10 & ZN5 & 345.6 & 1728.2 & 50.9 & 54.0 & 133.7 & 139.6 & 197.1 & 194.6 & 1.3 \\
\hline
\end{tabular}

The tensioning process curve of channel $\mathrm{ZN} 8$ is the changing trend of tensioning force and displacement during the tensioning process, as shown in Figure 14. Comparing and analyzing the initial and control prestressing forces with the theoretical standard values during the job process can provide a favorable basis to determine the tensioning job results, as shown in Figure 14a,b. According to the requirement of tensioning operation, the tensioning force should be kept for at least $20 \mathrm{~s}$ when it reaches the theoretical initial force. When the tensioning force reaches the theoretical control force, it should be kept at least for $5 \mathrm{~min}$. Therefore, we can use the curve in Figure 14a,b to analyze whether the tensioning work meets the requirements. In Figure $14 \mathrm{c}, \mathrm{d}$, the comparison and analysis of tensioning forces and displacement at both ends can also provide data support and decision-making basis for the subsequent adjustment of control parameters.

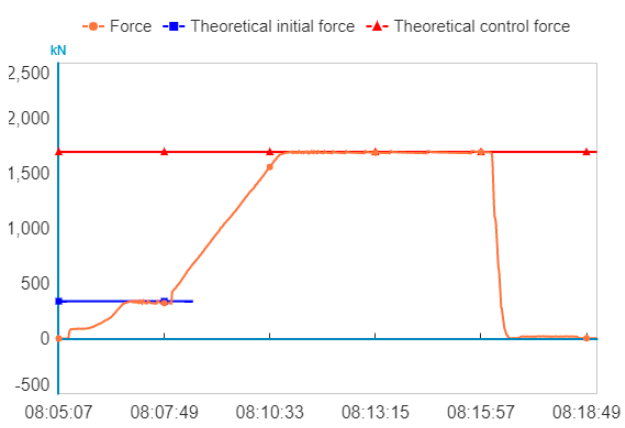

(a)

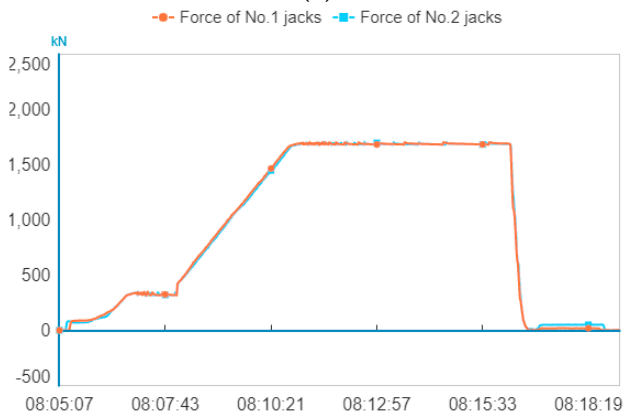

(c)

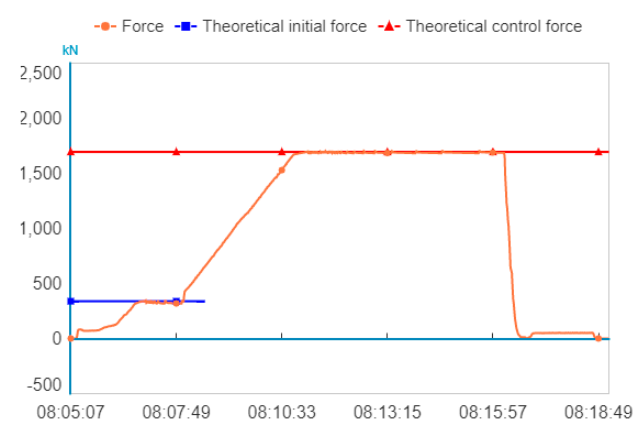

(b)

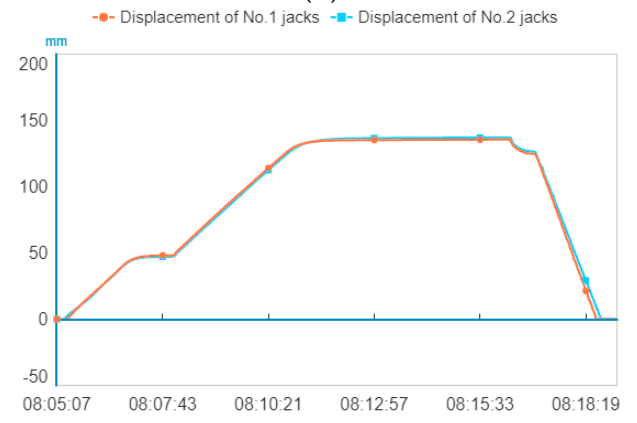

(d)

Figure 14. Tensioning data browsing. (a) Comparing and analyzing forces of No. 1 jacks. (b) Comparing and analyzing forces of No. 2 jacks. (c) The comparison of forces of No. 1 and No. 2 jacks. (d) The comparison of displacement of No. 1 and No. 2 jacks.

\subsubsection{Job Statistics Analysis}

The application service layer extracts the time and various control indicators in the job data and statistically analyzes the results of the tensioning job in line with the rules in the business rule 
base. The trends of job numbers, passing are shown by curves in month, as illustrated in Figure 15a. In this figure, the solid line represents the number of job numbers and the dotted line represents the number of job numbers. It can be seen from the figure that the two numbers are very similar, resulting in the two curves approaching coincidence. The trends of passing rates are shown by curves in month, as shown in Figure 15b. As can be seen from the figure, the passing rate is between 98.76 and 100 . Visualized statistical analysis can provide a decision-making basis for follow-up adjustments and quality controls.

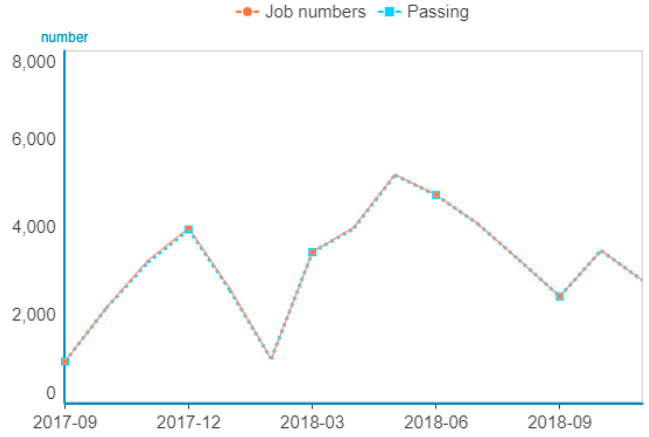

(a)

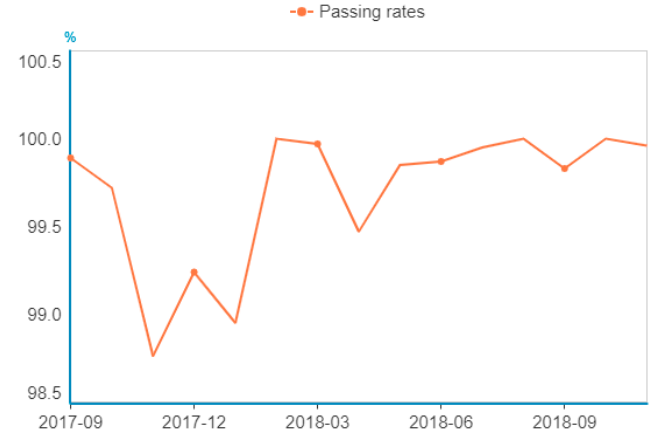

(b)

Figure 15. Statistical analysis. (a) The analysis of job numbers and passing. (b) The analysis of passing rates.

Although the traditional tensioning system provides such functions as automatic data acquisition and control, it lacks functions such as remote monitoring, visual analysis, and early warning pushing. When an abnormality occurs during the tensioning process, the abnormal data cannot be actively pushed to the operation manager in time. The data collected by the traditional tensioning system are only stored on the control computer of the job site, which may lead to the risk of tampering with the job data by the operator, thus failing to ensure the authenticity and validity of the job data. Through the system designed in this paper, the risk of false data can be reduced, and the data of tensioning operation can be analyzed by various curves, which is beneficial to improve the quality management of the tensioning operation. The main differences between the traditional tensioning system and the system designed in this paper are shown in Table 6.

Table 6. Contrast between traditional and the system designed in this paper.

\begin{tabular}{|c|c|c|c|}
\hline No. & Comparison & Traditional Tensioning System & System in This Paper \\
\hline 1 & Data authenticity & $\begin{array}{l}\text { Managers cannot remotely monitor the } \\
\text { tensioning operation, and cannot obtain } \\
\text { the key control data during the } \\
\text { tensioning operation in time. When an } \\
\text { abnormality occurs during the } \\
\text { tensioning process, the operator may } \\
\text { tamper with the data and there is a risk } \\
\text { of virtual data. }\end{array}$ & $\begin{array}{l}\text { When tensioning devices are started, job } \\
\text { messages are automatically pushed to the } \\
\text { mobile terminal app. Job data during the } \\
\text { process are monitored via mobile terminal } \\
\text { apps or browsers at any time. The changing } \\
\text { trends of tensioning and displacement are } \\
\text { reflected through continuous curves. }\end{array}$ \\
\hline 2 & $\begin{array}{l}\text { Exception handling } \\
\text { timeliness }\end{array}$ & $\begin{array}{l}\text { When an anomaly occurs, the abnormal } \\
\text { information is recorded on the site } \\
\text { control engine and cannot be pushed to } \\
\text { the administrator in time. It is difficult } \\
\text { for administrators to find abnormal } \\
\text { tension information in time and make } \\
\text { timely decisions. }\end{array}$ & $\begin{array}{l}\text { A problem base is generated automatically } \\
\text { in accordance with the alert rules, and the } \\
\text { abnormal information is pushed to the } \\
\text { administrator's mobile terminal apps to } \\
\text { spot abnormal information in time. } \\
\text { Administrators can make timely decisions } \\
\text { based on abnormal information. }\end{array}$ \\
\hline 3 & Fill in the data workload & $\begin{array}{l}\text { The operator needs to manually record } \\
\text { all kinds of key control data generated } \\
\text { during the tensioning process, which } \\
\text { increases the workload of the operator. }\end{array}$ & $\begin{array}{l}\text { System automatically record various types } \\
\text { of control data, and automatically generate } \\
\text { various types of data reports according to } \\
\text { application rules, avoiding manual filling } \\
\text { of large amounts of data. }\end{array}$ \\
\hline 4 & $\begin{array}{l}\text { Viewing data } \\
\text { convenience }\end{array}$ & Job data only can be checked on-site. & $\begin{array}{l}\text { Historical job data can be viewed through } \\
\text { mobile terminal apps or browsers. }\end{array}$ \\
\hline
\end{tabular}




\section{Conclusions}

This study proposes an IoT-based sensing model and its overall technical architecture by using IoT, computers, and communication technologies for the tensioning management of prestressed concrete beams. Three aspects are described: the sensing, transport, and application layers. The data collection and preprocessing of the sensing layer, the data-pushing mechanism of the transport layer, and the specific work division and the work flow of the application service layer are designed. App terminals and web pages are used as display media. The application system based on the technical framework in this study is applied to the Hubei section of Zhengzhou-Wanzhou high-speed railway for verification. The feedback shows four points. First, job notifications are pushed actively, job site construction is monitored remotely, and management methods and levels are improved. Second, automated data collection reduces human interventions and the risk of false data. Third, intelligent analysis and statistics provide data support for subsequent process upgrades and construction progress control decisions. Fourth, intelligent data processing and synthesis reduces complicated data entry work and improves work efficiency.

This research can be expanded in three aspects considering the application scenario of precast beam fields. First, the encapsulated structure of data can be optimized, and the amount of data transport can be reduced. Second, an in-depth study of the relationship between the tensioning process curve and the conclusions can be conducted. Tensioning equipment can be regulated in advance, and the qualified rate of tensioning results can be improved through analysis. Third, an app based on the ISO system can be developed. Otherwise, the intelligence of the system for decision making, perception, and equipment fault diagnosis, etc. also needs to be furthered.

Author Contributions: Design and implementation, X.C.; Analysis and testing, G.Y.; All authors contributed to editing and reviewing the manuscript.

Funding: This research was partially supported by National Natural Science Foundation of China under Grant nos. 61863005 and 91746116 and 61562011, the Science and Technology Foundation of Guizhou Province under grant PTRC[2018]5702, LH[2016]7381, and LH[2016]7433, Foundation of Key Laboratory of Advanced Manufacturing Technology of Ministry of Education, and the Student innovation and entrepreneurship training program under grant 201610660006.

Conflicts of Interest: The authors declare no conflict of interest.

\section{References}

1. Guo, T.; Chen, Z.; Liu, T. Time-dependent reliability of strengthened PSC box-girder bridge using phased and incremental static analyses. Eng. Struct. 2016, 117, 358-371. [CrossRef]

2. Otero-Chans, D.; Estévez-Cimadevila, J.; Martín-Gutiérrez, E. Application of a New System of Self-Tensioning to the Design of Large-Span Wood Floor Framings. J. Struct. Eng. 2016, 142, 04016012. [CrossRef]

3. Qian, K.; Yang, T.; Li, B. Progressive Collapse Resistance of Prestressed Concrete Beam-Column Sub-assemblages with Unbonded Post-Tensioning Strands. J. Struct. Eng. 2018, 144. [CrossRef]

4. Gosaye, J.; Gardner, L.; Wadee, M.A. Tensile performance of prestressed steel elements. Eng. Struct. 2014, 79, 234-243. [CrossRef]

5. Oh, B.H.; Si, N.L.; Lee, M.K. Analysis and Prediction of Transfer Length in Pretensioned, Prestressed Concrete Members. ACI Struct. J. 2014, 111, 549-560. [CrossRef]

6. Cowan, H.J. The strength of plain, reinforced and prestressed concrete under the action of combined stresses, with particular reference to the combined bending and torsion of rectangular sections. Mag. Concr. Res. 2015, 5, 75-86. [CrossRef]

7. Iqbal, M.A.; Rajput, A.; Gupta, N.K. Performance of prestressed concrete targets against projectile impact. Int. J. Impact Eng. 2016, 110, 15-25. [CrossRef]

8. Lachowicz, M.; Nagrodzka-Godycka, K. Experimental study of the post tensioned prestressed concrete corbels. Eng. Struct. 2016, 108, 1-11. [CrossRef]

9. Liao, M.; Ding, X.; Wen, X. Intelligent Stretching of Prestressed Precast Box Girder of Highway and Grouting Construction Technology. Constr. Technol. 2016, s2, 343-345. 
10. Dong, X.; Yu, X. Application of Prestressed Intelligent Tensioning System in Prefabricated Box Girder. Highway 2013, 9, 113-115.

11. Liang, X.D. Development of Intelligent Synchronous Prestress Tension System. J. China Foreign Highw. 2013, 33, 106-108.

12. Xiao, Y.; Zhang, T.; Chen, Y. Intelligent Tension Equipment Calibrating System. CN 203629866 U, 4 June 2014.

13. Yang, Q.; Chen, X. Intelligent tension large circulation grouting construction technology. Highway 2014, 7, 188-191.

14. Xiong, X. Development and Application of Prestressed Intelligent Tensioning Technology Based on Internet of Things. Constr. Technol. 2015, 44, 55-59.

15. Yao, X.; YU, M.; Chen, Y. Connotation, architecture and key technologies of Internet of manufacturing things. Comput. Integr. Manuf. Syst. 2014, 20, 1-10. (In Chinese)

16. Hou, R.; Ding, X.; Tao, Y. Internet of manufacturing things and relevant technical architecture. Comput. Integr. Manuf. Syst. 2014, 20, 11-20. (In Chinese)

17. Yang, J.J.; Fu, C.H.; Dong, Z.Q. Research and Design of Remote Surveillance System Based on the Internet of Things. Adv. Mater. Res. 2014, 889-890, 671-675. [CrossRef]

18. Yang, G.C.; Li, S.B.; Hu, Y. Project Image Progress Parametric Generating System for Railway Engineering. J. Wuhan Univ. Technol. Transport. Sci. Eng. 2009, 33, 246-249.

19. Zhan, C.; Fan, Y. Complex event processing of real time enterprises based on smart items. Chin. J. Mech. Eng. 2007, 43, 22-32.

20. Lu, Y.J.; Cecil, J. An Internet of Things (IoT)-based collaborative framework for advanced manufacturing. Int. J. Adv. Manuf. Technol. 2016, 84, 1141-1152. [CrossRef]

21. Zhang, Y.; Zhang, G.; Wang, J. Real-time information capturing and integration framework of the internet of manufacturing things. Appl. Mech. Mater. 2015, 121-126, 4059-4063. [CrossRef]

22. Zhao, X.; Zhang, Y.; Sun, S.; Wang, J.; Si, S. Implementing method and key technology for IoT-based manufacturing execution system. Comput. Integr. Manuf. Syst. 2012, 18, 2634-2642.

23. Tao, F.; Zuo, Y.; Xu, L.D. IoT-Based Intelligent Perception and Access of Manufacturing Resource toward Cloud Manufacturing. IEEE Trans. Ind. Inform. 2014, 10, 1547-1557.

24. Chen, W.; Li, S.; Huang, H. Active perception and management model for manufacturing data in discrete IoMT-based process. Comput. Integr. Manuf. Syst. 2016, 22, 166-176.

25. Huang, G.Q.; Zhang, Y.F.; Jiang, P.Y. RFID-based wireless manufacturing for real-time management of job shop WIP inventories. Int. J. Adv. Manuf. Technol. 2008, 36, 752-764. [CrossRef]

26. Li, X.; Gao, H.; Qiao, Y. Real-time Complex Event Processing Engine in Internet of Things. J. Chin. Comput. Syst. 2015, 36, 2047-2052.

27. Li, S.; Chen, W.; Hu, J. ASPIE: A Framework for Active Sensing and Processing of Complex Events in the Internet of Manufacturing Things. Sustainability 2018, 10, 692. [CrossRef]

28. Akl, A.; Saiidi, M.S.; Vosooghi, A. Deflection of in-span hinges in prestressed concrete box girder bridges during construction. Eng. Struct. 2017, 131, 293-310. [CrossRef]

29. Islam, M.S.; Lee, J.C.; Chong, U. Design and implementation of an automated monitoring system. J. Supercomput. 2016, 72, 4247-4261. [CrossRef]

30. Lian, J.H.; Hui-Min, L.I.; Sun, K. Design of Poultry Farming Environment Remote Monitoring System Based on Internet of Things. Poultry Sci. 2015, 7, 7-10.

(C) 2019 by the authors. Licensee MDPI, Basel, Switzerland. This article is an open access article distributed under the terms and conditions of the Creative Commons Attribution (CC BY) license (http://creativecommons.org/licenses/by/4.0/). 